\title{
Utilização e avaliação de software educacional para ensino de equilíbrio químico
}

Francielle Siqueira franciellesiqueira@gmail.com 0000-0002-1857-9378 Universidade Estadual de Maringá Maringá, Paraná

Ourides Santin Filho osantin@uem.br

0000-0001-5128-5390 Universidade Estadual de Maringá, Maringá, Paraná

Marcelo Maia Cirino

mmcirino@uel.br

0000-0002-5377-382X

Universidade Estadual de Londrina, Londrina, Paraná

\section{RESUMO}

A interação entre aluno e conteúdo através da utilização de softwares educacionais pode favorecer uma postura mais ativa na construção do conhecimento, e também, contribuir para a significação do conteúdo científico. Este artigo apresenta os resultados parciais de uma investigação cujo objetivo é a utilização e avaliação do software educacional "The Law of Mass Action" no ensino do Equilíbrio Químico. Através de uma proposta didática constituída por quatro encontros, aplicada a alunos do segundo ano do ensino médio, foi possível identificar as potencialidades e limitações do software enquanto ferramenta educacional. A constituição dos dados conta com observação, registros de áudio e questionários. A análise e interpretação, dá-se a partir dos pressupostos da Análise Textual Discursiva (MORAES, GALIAZZI, 2011) e da Teoria da ação Mediada (WERTSCH, 1999), permitindo identificar graus de domínio e apropriação dos alunos em relação ao equilíbrio químico após interação com o software.
\end{abstract}

PALAVRAS-CHAVE: Softwares educacionais. Teoria da Ação Mediada. Equilíbrio químico. 


\section{INTRODUÇÃO}

O interesse por tecnologia é crescente e quase incontrolável entre os estudantes. A novidade tecnológica que os acompanham diariamente é um aparelho de telefonia móvel (smartphone) com acesso à internet e, consequentemente, acesso às redes sociais, substituindo facilmente livros e cadernos. De acordo com pesquisa TIC2016 ${ }^{1}$ realizada pelo Comitê Gestor de Internet do Brasil, $88 \%$ dos indivíduos habitantes na região sul acessam diariamente a internet. A mesma pesquisa indica que entre os jovens de 10 a 15 anos de idade esse percentual é de $80 \%$. Nesta faixa etária, $69 \%$ destes jovens afirmam utilizar a internet para realizar atividades e pesquisas escolares.

No entanto, ter acesso à internet e utilizar o computador diariamente, não garante que este jovem saiba utilizar as Tecnologias da Informação e Comunicação (TIC) em benefício de sua formação educacional. Assim, torna-se um desafio para o professor não apenas competir com essas tecnologias, mas incorporá-las à sua prática docente e orientar estes jovens a aproveitarem de forma consciente e responsável tamanha fonte de informação.

Uma boa opção para utilizar as TIC no ensino de Ciências, em especial no ensino de Química, são os programas ou softwares educacionais. Trata-se de recursos educacionais abertos (REA) que compreendem simuladores e animações, e que estão disponíveis gratuitamente em diversas plataformas online. Tais recursos podem ser aproveitados como ferramenta pedagógica e facilitar a abordagem dos conteúdos científicos.

Pesquisas relacionadas ao tema revelam que uso das TIC tem contribuído para construção de significados de conteúdos científicos, como afirma Cirino:

\footnotetext{
[...] a utilização de uma ferramenta sociocultural como os Objetos de Aprendizagem, em ambientes de ensino, não apenas facilita a ação e aumenta sua eficácia, como também pode modificar de maneira substancial a forma e o caráter dessa ação e a própria estrutura das funções mentais empregadas (CIRINO, 2012, p.213).
}

Ainda nessa perspectiva, apontamos a pesquisa realizada por Oliveira, que investigou sobre a utilização de dois softwares no ensino do conteúdo de Gases Ideais, no nível Médio. A proposta, aplicada a estudantes do Ensino Médio, evidencia a interferência positiva dos recursos na construção de significados por parte dos pesquisados: "[...] entendemos que houve uma notável interferência dos REA na significação dos enunciados relacionados ao nosso tema de estudo" (OLIVEIRA, 2015, p. 157).

As duas investigações acima citadas fazem uso da Teoria da Ação Mediada, elaborada por James $\mathrm{V}$. Wertsch para análise dos dados. Na Teoria da Ação Mediada, detalhada na obra Mind As Action (1997), Wertsch, buscou explicar e entender como ferramentas culturais colaboram para a aprendizagem através da ação do homem. Neste contexto, o computador, em especial, os softwares de simulação e animação, são as ferramentas culturais que servem para mediar a construção do conhecimento.

Diante destas considerações, apresentamos uma proposta didática que visa elucidar questões como: pode o software educacional "The Law of Mass Action" contribuir para a compreensão do conteúdo de Equilíbrio Químico? Como o 
professor pode incorporar o uso dessas tecnologias em suas aulas? Qual é a aceitação do público alvo diante da nova abordagem?

Estabelecemos como objetivo geral a verificação do potencial pedagógico do software educacional "The Law of Mass Action" para o ensino do Equilibrio Químico, com ênfase na construção dos conceitos de reversibilidade de reação e a relação entre a constante de equilíbrio e a formação de produtos, numa reação química. Dentre os objetivos específicos destacamos: utilização de simuladores como ferramenta de mediação entre alunos e conteúdo; análise do processo de aprendizagem à luz da Teoria da Ação Mediada, de James Wertsch, com base na noção de domínio e apropriação.

\section{RECURSOS DIDÁTICOS DIGITAIS E TEORIA DA AÇÃO MEDIADA}

De acordo com Leite (2015, p.239) compreendem os recursos didáticos digitais (RDD): "todos os objetos de aprendizagem, produzidos com o uso das tecnologias digitais, que auxiliam no processo de aprendizado do indivíduo". Ainda sobre esses recursos, o autor destaca que sua utilização "faz com que o aluno desenvolva sua criatividade, tornando-se ativamente participante de construções cognitivas", por estimular a criatividade através de mecanismos audiovisuais.

Neste trabalho, adotamos como Software Educacional o RDD "The Law of Mass Action", avaliado enquanto ferramenta educacional com potencialidades para contribuir na elaboração de significados a respeito do conteúdo Equilíbrio Químico. Do ponto de vista conceitual, softwares "são programas que fazem a mediação de comunicação entre um sistema informático e seus usuários. É a parte lógica do computador". Já o "software educacional é aquele que pode ser usado para algum objetivo educacional qualquer que seja a natureza ou a finalidade para a qual tenha sido criado" (LEITE, 2015, p.175-176).

Existe, atualmente, uma vasta quantidade de RDD. Valente (1993, p. 9-11) os classifica em: programas tutoriais, programas de exercício e prática, jogos educacionais, simulações e animações. Sendo que os programas tutoriais e os de exercício e prática não permitem, na visão do autor, uma abordagem construcionista. Uma vez que apenas reproduzem informações, tal qual o livro didático, esses softwares não propiciam a participação ativa do usuário como ocorre com os simuladores.

Valente (1993) esclarece ainda que uma abordagem construcionista é sinônima da construtivista, pois permite que o aluno seja construtor de seu conhecimento. A adoção do termo construcionista por Valente, se estabelece quando o software utilizado permite a construção de algo, seja um texto, uma tabela, um gráfico, ou utilize dados de uma simulação. A interação do aluno com o computador é a via de construção do conhecimento.

De acordo com Giordan (2008, p.196): “[...] o desenvolvimento de aplicativos computacionais para atividades de ensino apresenta-se como uma alternativa potencialmente transformadora das práticas escolares [...]". Ao destacar as potencialidades dos softwares de animações e simulações Giordan os define, e esclarece que a diferença entre esses recursos esteja basicamente na forma de visualizá-los. 
Animações computacionais são geradas a partir de aplicativos gerais de edição gráfica, sem necessariamente incluir valores empíricos de propriedades das substâncias ou das transformações obtidos em pesquisa científica, e intencionam enfatizar determinadas características superficiais macroscópicas ou submicroscópicas sem considerar escalas de tempo ou de tamanho. Já as simulações computacionais são geradas a partir de aplicativos específicos para estudo de propriedades de substâncias e transformações químicas que estão intimamente relacionados ao ambiente de pesquisa científica. Para realizar estas simulações são utilizados valores teóricos ou empíricos de propriedades químicas [...] (GIORDAN, 2008, p.197).

Ao citar Johnstone, Giordan (2005, p.177), esclarece que "o conhecimento químico é construído pela articulação de três dimensões da realidade: macroscópica, submicroscópica e representacional". Operar o conhecimento transitando nessas três dimensões, conhecidas por Triângulo de Johnstone, parece ser trivial para um professor de Química, porém para o estudante existem grandes dificuldades, especialmente no campo representacional. "Parece existir uma dificuldade maior por parte dos estudantes em compreender o nível simbólico, pelo fato de os mesmos serem, respectivamente invisíveis e abstratos" (GIORDAN, 2008, p.180).

O uso de simuladores no ensino de Química é importante para elucidar essas confusões apresentadas pela maioria dos estudantes, uma vez que melhoram a capacidade de abstração, auxiliando também na compreensão dos níveis representacionais (simbólico) e também, submicroscópico (atômico - molecular). Muitos são programados para permitir ao usuário, nas palavras de Giordan (2008, p.181): "a representação imagética da entidade molecular do que supomos ocorrer na dimensão submicroscópica da matéria".

No que compete ao ensino de Química, exemplificamos aqui três repositórios que reúnem simuladores e animações extremamente úteis como ferramenta de mediação. O portal dia a dia educação <www.diaadiaeducacao.pr.gov.br> disponibiliza recursos didáticos digitais divididos por disciplinas e que podem ser utilizados online pelos educadores. $\mathrm{O}$ portal PhET $<$ http://phet.colorado.edu/pt_BR/>, vinculado à Universidade do Colorado, Estados Unidos, disponibiliza gratuitamente uma ampla diversidade de simuladores. E ainda, a plataforma Wolfram Education, <http://demonstrations.wolfram.com/index.html> escolhida por nós neste trabalho, que reúne simuladores nas diversas áreas de conhecimento, inclusive para o ensino superior.

O software educacional escolhido para investigação de suas potencialidades foi o The Law of Mass Action, um recurso educacional aberto disponível no repositório Wolfram Alpha, disponível no sítio da Wolfram Demonstration Projects (http://demonstrations.wolfram.com/index.html), projeto desenvolvido pela Wolfram Research, empresa criada em 1987 e especializada no desenvolvimento de softwares e incubadora de inovações técnicas e científicas.

A plataforma conta com uma seção inteiramente dedicada à educação, a Wolfram Education. Dentro desta plataforma há uma enorme variedade de simuladores, que podem ser acessados virtualmente por usuários através de diferentes dispositivos, computadores de mesa, computadores portáteis, além de dispositivos móveis iOS. 
A figura 1 mostra a tela de apresentação do programa, com seus botões e recursos principais. Acima, as barras representativas das concentrações dos reagentes $A$ e $B$ e do produto $C$. No centro, em destaque, os cilindros que representam sempre a situação inicial e a situação final de uma hipotética reação química, após terem sido ajustados convenientemente os parâmetros de concentrações. Os diferentes participantes da reação ( $A, B$ e $C$ ) são identificados por diferentes cores, vermelho, verde e azul respectivamente. Estão representados também a equação química genérica da reação em equilíbrio bem como a expressão algébrica da constante de equilíbrio.

Figura 1 - Interface do software The Law of Mass Action

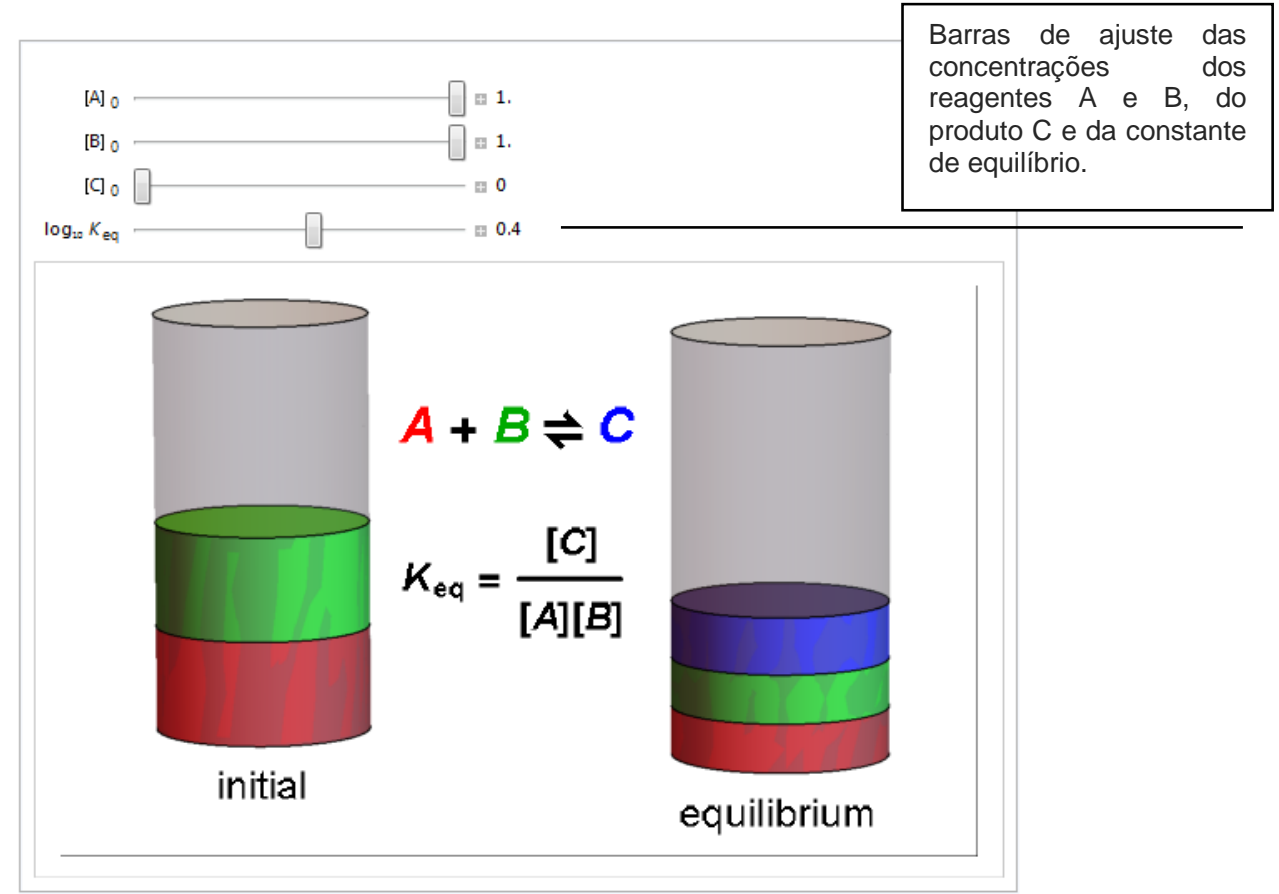

(Fonte: Software The Law of Mass Action - autor)

Uma preocupação inerente à utilização dos softwares educacionais no processo de ensino aprendizagem diz respeito à possibilidade de avalia-los quanto a sua eficácia na construção do conhecimento. A exemplo das pesquisas já citadas anteriormente, Cirino (2012) e Oliveira (2015), utilizamos aqui a Teoria da Ação Mediada, de James Wertsch, para analisar os graus de domínio e apropriação da ferramenta por parte dos participantes.

James V. Wertsch é estadunidense, professor nos departamentos de antropologia, psicologia e departamento de educação da Washington University em St. Louis, Estados Unidos. Graduou-se bacharel em Psicologia, realizou mestrado na área da educação e tornou-se doutor em Psicologia da Educação na Universidade de Chicago em 1975. Realizou um ano de pós-doutorado em Moscou, onde aprofundou seus estudos no sociointeracionismo de Vygotsky, Leontiev e Luria. Na atualidade dedica seus estudos à compreensão de como as escolas e outras Instituições do Estado são utilizadas para criar e manter a memória coletiva oficial. Em 1997 publicou a obra Mind as Action na qual apresenta e discute sua Teoria da Ação Mediada. 
Em sua teoria, Wertsch discute os processos de internalização de Vygotsky, incorpora os pressupostos de Mikhail M. Bakhtin quanto à dialogia e gêneros do discurso, e também os pressupostos de Keneth Burke quanto às múltiplas perspectivas da ação humana. Para Wertsch, quase toda ação humana resulta da interação com uma ferramenta cultural, sua teoria difere-se do sociointeracionismo de Vygotsky ao admitir um sistema de memória coletiva entre agente e ferramenta, para marcar essa distinção Wertsch adota o termo sociocultural.

\begin{abstract}
A ação mediada pressupõe que a "ação humana", incluindo a ação mental, tipicamente emprega meios mediacionais, ou ferramentas culturais que estão disponíveis em um cenário sociocultural particular. Tais ferramentas culturais, como a linguagem e os instrumentos de trabalho, moldam a ação humana de maneira essencial. E devido ao fato de que essas ferramentas são fornecidas por um cenário sociocultural particular, a ação humana é inerentemente "situada" em um contexto cultural, histórico e institucional (PEREIRA; OSTERMANN, 2012, p.26).
\end{abstract}

Dentre os exemplos apresentados por James Wertsch em La Mente em Acción para ilustrar a relação entre agente e ferramenta cultural, trazemos o bastante conhecido da "vara de saltar". Wertsch (1999) aponta que a adoção de uma vara (ferramenta cultural) permitiu ao agente (homem) saltar alturas cada vez maiores. Ainda decorre que desde a criação dos jogos olímpicos modernos, em 1896, os recordes olímpicos têm crescido exponencialmente na medida em que o material que constitui a ferramenta evolui.

Neste exemplo, o atleta (agente) sozinho não é capaz de saltar grandes alturas, a vara (ferramenta) também não é capaz de projetar o atleta por conta própria, deste modo, torna-se impossível pensar agente e ferramenta cultural de maneira isolada. "Na realidade, ferramentas culturais como as varas de salto (...) são incapazes de fazer algo por si mesmas. Somente podem ter efeito quando operadas por um agente" (WERTSCH, 1999, p.58).

Desta forma, cria-se uma "tensão irredutível" entre agente e ferramenta, termo designado por James Wertsch para explicar que agente e ferramenta não são capazes de operar isoladamente. Proveniente dessa relação entre agente e ferramenta, resultam dois conceitos criados por Wertsch para definir de maneira diferenciada o processo de internalização. No primeiro deles, segundo Wertsch (1999, p.89), determinadas ações mais simples não resultam num processo de internalização; para essas ações é preferido uso do termo "domínio" ou "saber como".

Termos menos confusos e carregados como "domínio", ou "saber como", me parecem preferíveis e precisamente por isso uso essas palavras no lugar de internalização, para analisar processos tais como andar de bicicleta ou falar um idioma (Wertsch, 1999, p.92).

De acordo com Giordan (2005, p 281): "Trabalhar com os conceitos de "domínio" e de "saber como" nos permite eliminar algumas noções que o conceito de internalização encerra, como por exemplo, trazer para o plano interior". Isto significa que Wertsch admite que a maioria das ações realizadas pelo homem não resulta num processo de internalização.

A ideia de apropriação relaciona-se a tomar para si, tornar próprio, trazer algo do outro e tornar seu. Trata-se de um processo de internalização mais complexo, 
e não se resume a apenas operar com habilidade a ferramenta cultural, mas pensar em conjunto com ela. "É possível que alguém domine, mas não se aproprie de uma ferramenta cultural, como é possível, também, que domínio e apropriação estejam correlacionados em alto ou baixo grau" (GIORDAN, 2005, p. 282).

Retomando o exemplo da vara de saltar, o atleta não apenas domina a ferramenta, (sabe operar corretamente a vara), como apropria-se dela, utilizandoa como extensão do próprio corpo para promover o salto. Nesta perspectiva, esperamos que a utilização do software educacional escolhido possa promover nos estudantes certo grau de domínio e apropriação, ou seja, saber operar o recurso e apropriar-se dele na construção do conhecimento científico.

\section{METODOLOGIA}

Optamos por realizar uma investigação de caráter qualitativo onde o foco é a interpretação dos dados e não a sua quantificação. Flick releva a importância dos aspectos a serem observados numa pesquisa qualitativa, como "a apropriabilidade de métodos e teorias; as perspectivas dos participantes e sua diversidade; a reflexibilidade do pesquisador e da pesquisa; além da variedade de abordagens e métodos na pesquisa qualitativa" (FLICK, 2009, p.23).

Para assegurar tais aspectos, propusemos uma sequência didática composta por quatro encontros de duas aulas cada (totalizando oito aulas) constituídos por atividades práticas (encontro 1); atividades de interação com software educacional (encontros 2 e 3); e atividades discursivas e reflexivas (encontro 4). Além da pesquisadora, participaram deste trabalho dez alunos do segundo ano do ensino médio do Colégio Estadual do Jardim Independência, na cidade de Sarandi, Paraná. Para preservar suas identidades, eles estão identificados pela letra inicial de seus nomes, seguidas de números em caso de letras coincidentes, desta forma os sujeitos da pesquisa encontram-se aqui denominados: D, E1, E2, I, K, L1, L2, M, R, e W.

A coleta de dados foi realizada em todos os quatro encontros tendo sido utilizados questionários com perguntas abertas, observação participativa da professora aplicadora, e gravação de áudio. Foram considerados como corpus da pesquisa os questionários aplicados em todos os encontros, trechos das gravações de áudio que permitiram identificar as principais ideias dos participantes, e as observações da pesquisadora.

Utilizamos a Análise Textual Discursiva (ATD) como referencial metodológico nesta investigação, uma vez que Moraes e Galiazzi (2011, p.11) afirmam que este tipo de pesquisa: "Não pretende testar hipóteses para comprová-las ou refutá-las ao final da pesquisa; a intenção é a compreensão, reconstruir conhecimentos existentes sobre os temas investigados".

Através da ATD buscou-se destacar unidades de significado nas diferentes respostas dos participantes. Sempre que necessário, realizou-se o confronto das respostas escritas com o registro em áudio, já que o discurso dos participantes pode se manifestar por diversos meios, como declaram Moraes e Galiazzi (2011, p.61): "Este esforço de captar mensagens conscientes e inconscientes implica um movimento de ultrapassagem de uma leitura de primeiro plano para outra de maior profundidade". 
As atividades foram desenvolvidas no laboratório de ciências da escola, na primeira semana do mês de fevereiro de 2016. O laboratório dispõe de amplo espaço físico e três grandes bancadas, uma boa quantidade de reagentes e vidrarias, tanques para lavagem, armários e quadro negro. Tanto o espaço físico quanto as normas de segurança para ocupá-lo já eram de conhecimento dos alunos por frequentarem o laboratório durantes as aulas de Química.

O primeiro encontro objetivou despertar o interesse pelo conteúdo e levantar algumas concepções prévias a respeito de reversibilidade e equilíbrio químico. Para tanto, foi proposto aos alunos a realização de duas atividades práticas, a primeira delas foi o aquecimento de pequena amostra de sulfato de cobre penta hidratado, e sua consequente mudança de cor tanto por aquecimento, quanto pelo posterior acréscimo de água ao sal desidratado. Numa segunda atividade, eles acrescentaram solução de ácido clorídrico em soluções de hidróxido de sódio contendo o indicador vermelho congo, realizando assim um experimento de equilíbrio químico envolvendo diferentes concentrações de ácido e base.

No segundo encontro, os alunos tiveram o primeiro contato com o software The Law of Mass Action. A princípio, tiveram liberdade para manipulá-lo e descobrir as respostas resultantes do uso de suas sub-rotinas. No mesmo encontro esse manuseio foi dirigido pela pesquisadora, através de algumas instruções simples para exploração das funcionalidades do software. Naquele momento, os participantes foram convidados a trazerem para o laboratório de Ciências seus computadores pessoais, de forma que, no dia do encontro seis notebooks estavam à disposição dos usuários, possibilitando assim, o trabalho em duplas.

O terceiro encontro foi reservado ao uso orientado do software, propusemos um roteiro procurando orientar os alunos a observar as variações no sistema químico representado, em função da modificação controlada das variáveis de concentração dos três compostos genéricos e do logaritmo da constante de equilíbrio. Aqui, o foco do encontro centrou-se na relação entre a constante de equilíbrio e formação de produto.

Por fim, o quarto e último encontro foi reservado à discussão sobre o equilíbrio químico em situações cotidianas, a saber, o experimento da "garrafa azul", o da evaporação da água em uma garrafa, e também, o equilíbrio gás-líquido numa garrafa de refrigerante. As discussões foram despertadas para avaliar o processo de evolução na construção do conhecimento a respeito do equilíbrio químico. Os resultados do questionário de avaliação final, aplicado no encerramento deste encontro, permitiu-nos estimar nuances de domínio e apropriação por parte dos estudantes, possibilitando, assim, maiores conclusões a respeito das potencialidades do software.

A aplicação de questionários nos quatro encontros, bem como o registro das discussões em áudio, gerou uma grande quantidade de dados, de forma que, neste artigo, apresentaremos apenas algumas questões para exemplificar a criação das seguintes categorias: C1: noções de processos reversíveis; $\mathrm{C} 2$ : concepções sobre equilíbrio químico; e C3: relação entre constante de equilíbrio e formação do produto. Nas considerações finais apresentaremos uma breve discussão a respeito da abordagem e sobre domínio e apropriação.

A busca de relações entre as diferentes respostas possibilitou a identificação 
criadas após a identificação das unidades de significados e seu reagrupamento, ou unitarização. Deste modo é possível a interpretação, não a partir do que foi dito, mas também, do que se pretende dizer.

\section{RESULTADOS E DISCUSSÕES}

\section{Noções de Processos Reversíveis}

As atividades práticas realizadas no primeiro encontro, permitiu-nos constatar, as primeiras concepções dos participantes a respeito da reversibilidade das reações químicas. Após aquecimento do sulfato de cobre penta hidratado e sua consequente mudança de coloração do azul para branco acinzentado, os participantes foram questionados sobre a causa da mudança de cor, e o porquê da cor azul voltar na adição de gotas de água. Obtivemos respostas como:

Participante I: "A água do sulfato de cobre sai por isso a cor azul some"

Participante E1: "Se deve a desidratação do sulfato de cobre"

Participante L1: "Se deve ao desidratamento do sulfato de cobre. Depois ao jogar água ele volta ao seu estado normal". (Sic)

Participante W: "O sulfato volta a sua cor normal"

Participante E2: "O experimento que era azul e com o aquecimento com água ele volta sua cor normal, devido á água que hidrata o sulfato de cobre."

As respostas nos mostram que houve compreensão do fenômeno ocorrido, e que os mesmos contribuíram para a significação do conceito de reversibilidade da reação. Destacamos a colocação do participante E1 pelo uso do termo "desidratação", linguagem adequada ao fenômeno químico observado. Já o participante L1 utilizou o termo "desidratamento", inexistente na língua portuguesa, mas que indica uma tentativa de aproximação da linguagem científica.

Consideramos aqui, que os termos "volta" e "voltou" sublinhados nas diferentes respostas para a segunda questão, constituem unidades de significado para reversibilidade, a nível macroscópico, observável no experimento. Os registros de áudio sugerem que tal significado pode ter sido construído ou reconstruído através das discussões emergentes durante a execução da referida atividade prática:

Participante W: "Voltou sim... tá ficando azul de novo"

Participante R: "voltou a mesma cor de antes"

Participante L2: "não voltou não..."

Participante R: "aí voltou a cor de antes gente... Alá... hidratou ele..."

A ideia de reversibilidade das reações foi abordada em todos os encontros, inclusive nos de interação com o software, porém foi resgatada, de forma muito direta, no questionário final através da questão: $O$ que caracteriza uma reação reversível? A maioria dos participantes respondeu satisfatoriamente à questão apresentando suas considerações sobre reversibilidade: 
M: "É quando ela tem o reagente e produto em equilíbrio, assim ela fica reversível".

W: "Uma reação reversível é uma reação que pode ocorrer dos dois lados"

L2: "É uma reação que pode ser feita e refeita várias vezes"

K: "Quando o produto volta a situação inicial, por exemplo: A água é congelada e após um tempo deixa exposto o calor, a água volta a situação inicial de líquido".

Os fragmentos destacados mostram aquisição de uma linguagem mais próxima da linguagem científica, pelo menos para a categoria C1 (noções de processos reversíveis). A exemplo, os participantes $L 1, M$, e K, que adotam uso das palavras "reagente", ou "produto", as concepções apresentadas encontram-se melhor elaboradas do que os termos "volta" e "voltou" que aparecem nas primeiras discussões. O progresso considerável na linguagem desses participantes pode ser resumido por Maldaner:

\begin{abstract}
Os conceitos científicos se enriquecem de vivência e concretude, indo ao encontro dos conceitos cotidianos, e estes se organizam, adquirindo novos significados, mais generalizantes, menos "pregados" na vivência. Mas nada disso acontece sem a mediação dos instrumentos próprios da escola (MALDANER, 2000, p.150).
\end{abstract}

\title{
Concepções sobre Equilíbrio Químico
}

Para exemplificar essa categoria, consideramos interessante destacar o episódio em que a pesquisadora levanta discussão a respeito do equilíbrio químico: "P: Equilíbrio Químico é um conteúdo de segundo ano que nunca dá tempo de trabalhar... aí vem minha perguntinha básica... o que vem na cabeça de vocês quando fala a palavra equilíbrio?". As respostas que seguem esta indagação nos dão ideia de uma concepção de equilíbrio estático.

M: ((risos)) símbolo yin-yang. ((risos))

L1: não cair ((risos))

W: (...) iguais

E2: duas partes equivalentes?

Na sequência, quando questionados sobre reações químicas em equilíbrio, a concepção é levada adiante:

$P$ : se eu pensar numa reação química... quando que eu posso dizer que uma reação química está em equilíbrio?

W: quando está metade-metade...

As palavras acima destacadas, "yin-yang", "iguais", "partes equivalentes" e "metade-metade", constituem, para esses participantes, unidades de significado para a concepção de equilíbrio. Tal concepção mostra-se fortemente enraizada no que se vivencia a respeito de equilíbrio estático de forças, como a figura de uma balança com dois pesos iguais em cada lado. Essa concepção prévia é levada do conhecimento cotidiano ou provém das aulas de Física para o conhecimento químico de maneira equivocada, ainda que inconsciente, e pode constituir um obstáculo epistemológico na linguagem de Bachelard. 
Os professores de ciências imaginam que o espírito começa como uma aula, que é sempre possível reconstruir uma cultura falha pela repetição da lição, que se pode fazer entender uma demonstração repetindo-a ponto a ponto. Não levam em conta que o adolescente entra na aula de física com conhecimentos empíricos já construídos: não se trata, portanto, de adquirir uma cultura experimental, mas sim de mudar de cultura experimental, de derrubar os obstáculos já sedimentados pela vida cotidiana (BACHELARD, 1996, p. 23).

Bachelard, na obra a Formação do Espírito Científico (1996) aponta uma série de obstáculos epistemológicos que, segundo ele, viriam atrapalhar a aprendizagem, dificultando a passagem do conhecimento cotidiano ou primário para um conhecimento científico. A experiência pessoal colocada acima da crítica, a opinião sem embasamento crítico, as generalizações e conclusões empíricas apressadas seriam, segundo o epistemólogo, os primeiros obstáculos que surgem de nossa vivência e contrapõem a construção de um novo conhecimento.

Após as interações com o software e discussões em grupo, os participantes são levados a repensar a concepção de equilíbrio químico ao responderem a uma questão de ocorrência cotidiana: Ao se abrir uma garrafa de refrigerante ouve-se um barulho que dura pouco. Explique com detalhes o que ocorreu. Nesse momento, o que acontece no líquido? Explique. $O$ processo acima é reversível com a garrafa fechada? E com a garrafa aberta?

A tabela 1 reúne algumas respostas para esta questão e as respectivas interpretações com base nas noções de domínio e apropriação, segundo a Teoria da Ação Mediada. Estão presentes interpretações em maior ou menor grau de domínio e apropriação, o que é comum na visão de Wertsch (1999, p.88): "É interessante observar que muitas, talvez a maioria, das formas de ação mediada nunca progridam em direção a sua realização num plano interno". Por esse motivo muitas de nossas interpretações referem-se a apenas domínio, especialmente quando há indícios que o sujeito da pesquisa "saiba como" utilizar a ferramenta cultural, mas não esteja "apropriando-se" dela.

Tabela 1 - Noções de domínio e apropriação sobre equilíbrio químico

\section{Posicionamento}

E1: Ao abrir a garrafa, o gás que estava comprimido sai imediatamente, já o gás que está no líquido, demora mais, o processo é reversível com a garrafa fechada, já com ela aberta não, porque o gás tende a sair.

L1: O que ocorre é o gás que sobe para a parte de cima da garrafa. O processo é reversível porque há gás no líquido e com a garrafa aberta o gás é liberado

E2: Após abrir e fechar a garrafa de refrigerante, o gás não sai totalmente, ele se equilibra de acordo com o líquido. $O$ gás sai mas não totalmente. Sim pode ser reversível, fechando a garrafa o gás se equilibra, já com a garrafa aberta o gás sai tudo

\section{Domíno/Apropriação}

Apropriação

Domínio

Pequeno grau de Apropriação 
M: O barulho é causado pela liberação do ácido carbônico e ela vai para a atmosfera. Ele é reversível se fechar a garrafa o gás ainda continua lá dentro e se abri-la o mesmo acontece

(Fonte: Autor)
Nenhum grau de domínio ou apropriação

Ao falar em "gás comprimido" e "processo reversível" num sistema fechado, o participante E1 parece ter se apropriado do software na elaboração de seu discurso, uma vez que em toda a simulação trabalha-se num sistema fechado. Além disso, o discurso como um todo demonstra uma compreensão clara do fenômeno e uso de linguagem apropriada para explicá-lo.

Foram interpretadas como domínio as respostas dos participantes cujo discurso apresentou pequenas confusões ou uso de linguagem inadequada, o que aconteceu na maioria dos casos, condição previsível de acordo com as palavras de Werstch:

Por fim, algumas formas muito interessantes de ação mediada se caracterizam pelo domínio no uso de uma ferramenta cultural, mas não por sua apropriação. Em tais casos de ação mediada, o agente pode usar uma ferramenta cultural, mas o faz com uma sensação de conflito ou resistência. (WERTSCH, 1999, p.97)

Uma parte dos pesquisados apresentou respostas completamente confusas, o que não condiz com nenhuma condição de domínio ou apropriação quando se trata de equilíbrio químico. Para esses participantes, o processo de internalização em menor ou maior grau parece estar em amadurecimento, necessitando uma atenção redobrada ou maiores interações com a ferramenta.

\section{Relação entre Constante de Equilíbrio e Formação do Produto}

Nos dois encontros em que há interação dos participantes com o software são exploradas questões que relacionam a constante de equilíbrio com a quantidade de produto formado. São elas: Como se relaciona a constante de equilíbrio e a formação do produto C?; e: De que maneira o aumento da Keq influencia a quantidade de produto formado?

Uma análise das respostas obtidas indica a influência da interação com o software no posicionamento dos participantes:

W: A mistura precisa de $\mathrm{K}$ elevado para $\mathrm{C}$ ser elevado

L1/M: Quanto maior Ke, maior C quanto menor o Ke menor a mistura A e B.

O objetivo dessa interação é atribuir significado para constante de equilíbrio das reações químicas, uma vez que nos livros didáticos são expressas apenas definições de maneira vaga, como aponta o trecho extraído do livro didático desses estudantes: "As constantes de equilíbrio representadas por K, são determinadas de dados experimentais. Em uma análise chegou-se a expressão genérica para todos os equilíbrios" (ANTUNES, 2013, p.87).

Nota-se que a frase destacada não garante nenhum significado para constante de equilíbrio, apenas informa que é um dado experimental representado pela letra K. A discussão que ressaltamos é que provavelmente a informação do livro didático não contribuiu para a elaboração de significado sobre a constante de equilíbrio, nem reforçou nos alunos a capacidade de pensar, o que é comum quando a 
abordagem de ensino é apenas instrucionista, como critica Valente (1998, p.50): “(...) Por outro lado, a análise dos resultados do paradigma instrucionista são desoladores: provocamos o êxodo do aluno da escola ou produzimos um educando obsoleto."

Considerações a respeito da constante de equilíbrio foram retomadas no encontro final, onde podemos constatar que alguns de nossos participantes passam a atribuir significado para a constante de equilíbrio numa reação química, fato evidenciado pelas respostas obtidas à seguinte questão:

Ao trabalhar com software educacional "The Law of Mass Action" exploramos a relação entre a constante de equilíbrio (Keq) e a formação de produtos numa reação química. Na indústria química, o estudo do ponto de equilíbrio e das maneiras de deslocá-lo são essenciais para a determinação do rendimento das reações. Supondo que você seja químico responsável por uma indústria e deve escolher uma reação no sentido de favorecer a formação do produto, como deverá proceder ao analisar reações químicas e seus valores de constante de equilíbrio?

Tabela 2: Noções de domínio e apropriação sobre constate de equilíbrio.

Posicionamento

Domíno/Apropriação

W: Para favorecer o produto, o valor da constante deve ser elevado.

E1: Deve-se aumentar a constante de equilíbrio.

K: Quanto mais Ke mais produto tem.

D: Pesar a quantidade do Keq das reações elevando ou diminuindo a formação do produto. Até estar em uma constante de equilíbrio. E pensar que quanto mais Keq mais equilíbrio terá o produto.

(Fonte: Autor)
Apropriação

Apropriação

Domínio

Nenhum grau de domínio ou apropriação.

Percebemos pelas falas dos dois primeiros participantes, W e E1, que houve apropriação do software na elaboração da resposta, ou seja, é provável que estes estudantes tenham compartilhado uma memória com o software educacional ao afirmarem: "o valor da constante deve ser elevado" e "aumentar a constante de equilíbrio". Industrialmente, aumentar a constante de equilíbrio de uma reação não é possível, constantes de equilíbrio são valores experimentais determinados para cada reação química, na prática não são variáveis que possam ser "aumentadas" ou "elevadas", porém tal condição é possível através da interação com o software, e este, dois participantes, consideraram essa possibilidade ao fornecer tais respostas.

A resposta do participante $\mathrm{K}$, foi interpretada como apenas domínio, por apresentar pequena confusão de linguagem, embora o contexto esteja correto. $O$ mesmo não ocorre com o participante D que considerou Keq com algo "pesável", ou seja, com um dos reagentes da reação, demonstrando grande confusão de ideias a respeito da constante de equilíbrio. 


\section{CONSIDERAÇÕES FINAIS}

Um primeiro olhar, faz-se necessário sobre a prática de incorporar TIC no ensino, através da qual comprovamos ser possível a utilização de softwares educacionais no ensino de ciências. Nossa experiência mostra que a elaboração de uma sequência didática envolvendo uso de tecnologias pode ser produtiva, especialmente quando aliada às atividades experimentais, como no nosso caso.

Através de uma sequência didática que envolveu quatro encontros de duas aulas cada, foi possível abordar alguns conceitos sobre equilíbrio químico como reversibilidade das reações e significação para a constante de equilíbrio. $\mathrm{O}$ uso do software The Law of Mass Action mostrou-se eficaz durante a abordagem a que nos propusemos, e também permitiu a identificação de algumas limitações do próprio programa.

A respeito da reversibilidade das reações químicas, constatamos que, desde a atividade prática, a concepção de que reações químicas podem ocorrer em dois sentidos, tornou-se amplamente aceita pelos participantes, e que o software contribuiu para consolidá-la conforme comprovamos na discussão da primeira categoria: Noções Sobre Processos Reversíveis.

A adoção de termos científicos por parte dos participantes, como "produto" e "reagente", evidencia o progresso no uso de linguagem apropriada, da ampliação do horizonte e do gênero discursivo e a tentativa de exemplificar a concepção através da citação de um exemplo que denota certo grau de apropriação, como no caso do participante K: "Quando o produto volta a situação inicial, por exemplo: $A$ água é congelada e após um tempo deixa exposto o calor, a água volta a situação inicial de líquido".

Em relação à construção coletiva do conceito de equilíbrio químico, segunda categoria por nós discutida, pudemos observar que, mesmo após utilização do software, prevaleceu a concepção prévia de que nas reações químicas há consumo total dos reagentes, ou seja, a existência de um equilíbrio estático, e a maioria dos participantes apresentou certo grau de domínio da ferramenta, ou seja, sabem utilizá-la adequadamente, porém não se apropriaram dela para elaboração de significados.

Não foi possível constatar a admissão por parte dos participantes que no equilíbrio coexistem quantidades significativas de produto, e também, de reagentes, mesmo porque o software apresenta aqui uma limitação: a representação das quantidades de reagentes e produtos por cores e não por partículas, com apelo à dimensão macroscópica e sem apelo à dimensão submicroscópica.

As atividades desenvolvidas no segundo e terceiro encontro mostraram-se eficientes no desenvolvimento de significado para constante de equilíbrio. Enquanto professora da educação básica, sei que a constante de equilíbrio é uma quantidade física que calculamos através de uma expressão matemática específica. Não há nos livros didáticos, e não havia na minha postura como professora de Química, a intencionalidade de atribuir significado para a expressão Keq. Através da utilização do software, os estudantes puderam identificar que, com o aumento da constante de equilíbrio ocorre aumento na quantidade de produto formado, atribuindo assim um significado para essa constante. 
Podemos afirmar, de maneira preliminar, que o software se mostrou eficiente para a abordagem do conteúdo equilíbrio químico, em especial na compreensão do fenômeno como um todo, e que proporcionou, ao menos a noção de domínio por parte dos participantes, o que ficou evidenciado pela análise das três categorias aqui apresentadas. A análise parcial dos resultados nos fornece subsídios no sentido de apontar que a atividade desenvolvida é muito válida, especialmente por ter aliado atividades experimentais e de simulação com uso das TIC. 


\title{
Use and evaluation of educational software for teaching chemical equilibrium
}

\begin{abstract}
Interaction between student and content through the use of educational software can favor a more active position in the construction of knowledge, and also contribute to the meaning of the scientific content. This article presents the partial results of an investigation whose objective is the use and evaluation of educational software "The Law of Mass Action" in the teaching of Chemical Equilibrium. Through a didactic proposal made up of four meetings, applied to the students of the second year of high school, it was possible to identify the potentialities and limitations of software as an educational tool. The constitution of the data counts with observation, audio records and questionnaires. The analysis and interpretation is based on the assumptions of the Discursive Textual Analysis (MORAES, GALIAZZI, 2011) and the Theory of Mediated Action (WERTSCH, 1999), allowing to identify degrees of dominance and appropriation of students in relation to chemical equilibrium after interaction with the software.
\end{abstract}

KEYWORDS: Educational softwares. Theory of Mediated Action. Chemical equilibrium. 
${ }^{1}$ A pesquisa TIC Domicílios é realizada anualmente desde 2005 com o objetivo de mapear o acesso à infraestrutura TIC nos domicílios urbanos e rurais do país e as formas de uso destas tecnologias por indivíduos de 10 anos de idade ou mais. A partir de 2013 a TIC Domicílios também incorporou em seu escopo a TIC Crianças, que investiga o uso de TIC entre indivíduos de 5 a 9 anos, e era realizada separadamente desde 2009. (http://cetic.br/pesquisa/domicilios/).

\section{REFERÊNCIAS}

ANTUNES, Murilo Tissoni. Química: 2 ano. 2. ed. Coleção Ser protagonista Edições SM. São Paulo, 2013.

BACHELARD, Gaston. A formação do espírito científico: contribuição para uma psicanálise do conhecimento. Esteia dos Santos Abreu trad. Contraponto. Rio de Janeiro, 1996.

CIRINO, Marcelo Maia. Objetos de Aprendizagem como ferramentas socioculturais para o ensino de Química. 306f. Tese (Doutorado em Educação para a Ciência). Faculdade de Ciências, UNESP, Bauru, 2012.

FLICK, Uwe. Introdução à pesquisa qualitativa. 3 ed. Artmed. Porto Alegre, 2009.

GIORDAN, Marcelo. O computador na Educação em Ciências: Breve Revisão Crítica Acerca de Algumas Formas de Utilização. Ciência e Educação. Vol.11, n02, p. 279-304, 2005.

Computadores e linguagens nas aulas de ciências: uma perspectiva sociocultural para compreender a construção de significados. 1. ed. ljuí: Unijuí, 2013. (Coleção educação em ciências).

LEITE, Bruno Silva. Tecnologias no ensino de química: teoria e prática na formação docente. 1 ed. Appris. Curitiba, 2015.

MALDANER, Otavio Aloisio. A formação inicial e continuada de professores de química: professor/pesquisador. Ed. Unijuí. Ijuí, 2000. (Coleção educação em química).

MORAES, Roque, GALIAZZI, Maria do Carmo. Análise Textual Discursiva. 2 ed. Unijuí Ed. ljuí, 2011. (Coleção Educação em Ciências) 
OLIVEIRA, Weslley Cabral de. Utilização e avaliação de softwares no ensino de gases ideiais: uma proposta de unidade didática para o ensino médio. 306f. Dissertação (Mestrado em Educação para Ciência e a Matemática) - Universidade Estadual de Maringá, Maringá, 2015.

PEREIRA, A. P.; OSTERMANN, F. A aproximação sociocultural à mente, de James V. Wertsch, e implicações para a educação em ciências. Ciência \& Educação. Bauru, v. 18, n. 1, p. 23-39, 2012.

VALENTE, José Armando. Computadores e Conhecimento: repensando a educação. 2 ed. UNICAMP. Campinas, São Paulo, 1998.

WERTSCH, James V. La mente en acción. 1. ed. Buenos Aires, AR. Aique, 1999, 304p. - (Colección Psicología Cognitiva y Educación).

WOLFRAM Demonstrations Project. The Law of Mass Action. Disponível em: <http://demonstrations.wolfram.com/search.html?query=the\%20law\%20of\%20 mass\%20action>. Acesso em 18/01/2017.
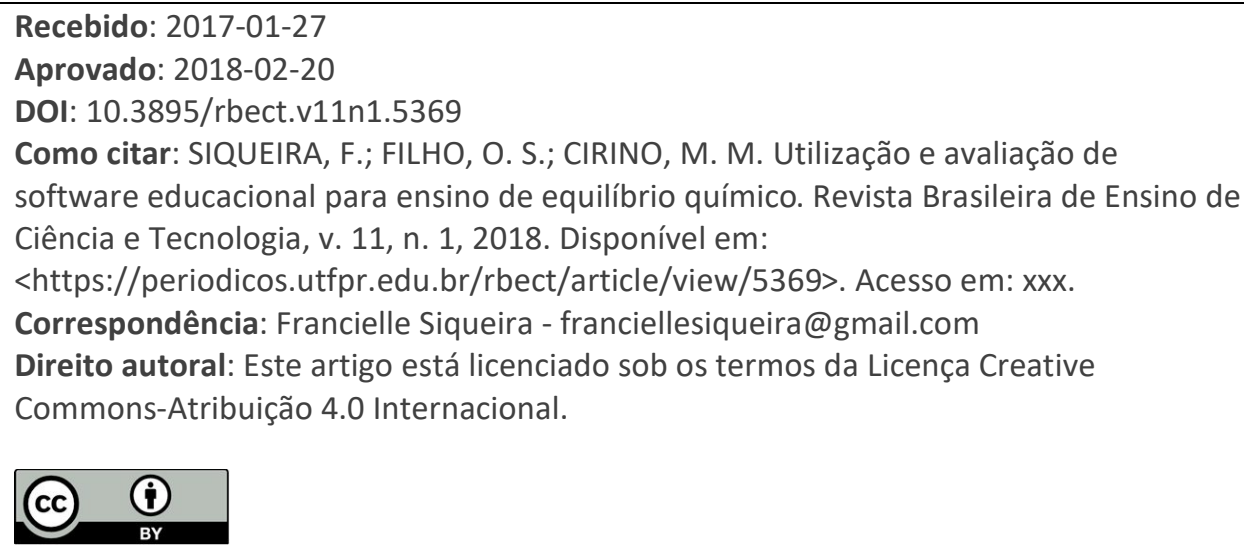